\title{
BM] Global Health Are formal self-care interventions for healthy people effective? A systematic review of the evidence
}

\author{
Nilushka Perera, ${ }^{1}$ Shade Agboola ${ }^{2}$
}

To cite: Perera N, Agboola S. Are formal self-care interventions for healthy people effective? A systematic review of the evidence. BMJ Global Health 2019;4:e001415. doi:10.1136/ bmjgh-2019-001415

Handling editor Seye Abimbola

Received 14 January 2019

Revised 8 April 2019

Accepted 13 April 2019

\section{Check for updates}

\section{(c) Author(s) (or their} employer(s)) 2019. Re-use permitted under CC BY-NC. No commercial re-use. See rights and permissions. Published by BMJ

${ }^{1}$ Evaluation, Impact and Policy, Best Beginnings, Battaramulla, Sri Lanka

${ }^{2}$ Public Health, Nottingham City Council, Nottingham, UK

Correspondence to

Nilushka Perera;

nilushka.p@gmail.com

\section{ABSTRACT}

Introduction Preventative interventions are shown to be effective in reducing $40 \%$ of the mortality due to unhealthy behaviours and lifestyles. Health-promoting self-care has been recognised as a promising strategy in preventative health. However, self-care research is being done around the self-management of chronic illnesses and the promotion of self-care practices among healthy populations has been overlooked by many healthcare systems.

Method The study methodology was a systematic review with a narrative synthesis. The search was done through seven academic databases, reference tracking of selected articles and grey literature. The scoping, selection, screening and quality assessments of the articles were reviewed independently by two reviewers.

Results Sixteen studies met the inclusion criteria. Selfcare behaviour, health-promotive lifestyle changes and medical care utilisation were some of the main outcomes evaluated in the studies. Positive effects were seen in increasing self-care and health-promotive behaviours in most interventions although limited or mixed impact was seen in health attitudes, beliefs and utilisation of medical services. Most studies were from high income settings with low-quality study designs. The complexity of the word 'self-care' and inconsistencies in the terminology used in health-promotive self-care were significant highlights of the study.

Conclusion Health-promoting preventative self-care interventions show promise in increasing the well-being of healthy people. However, the methodological drawbacks limit the generalisability of the findings. As the demand for self-care interventions increases, the lack of a formal globally accepted definition and framework and complexity of behaviour change are key limitations to consider moving forward.

\section{INTRODUCTION}

Preventative interventions, using healthpromotive strategies, have been shown to be effective in reducing up to $40 \%$ of the mortality caused by unhealthy behaviours and lifestyles. ${ }^{1}$ Health promotion, a core strategy in prevention, emerged in the 1980s creating a novel approach to public health interventions and practices. ${ }^{2}$ Self-care is a form of

\section{Key questions}

What is already known?

- Health-promotive self-care is a growing area of health promotion that shows significant promise in outcomes and reduced expenditure but there is much less attention given to health-promotive selfcare interventions for healthy populations.

What are the new findings?

- Current studies are of low to moderate quality and majority are from high-income countries limiting the strength of the pooled effects.

- There is a clear lack of consistency in the terminology used in self-care resulting in varying intervention design, restricting the comparability of studies.

What do the new findings imply?

- Develop a globally accepted definition and framework for health-promotive self-care and establish clear parameters of its use and definition.

- The need for more robust high-quality evaluation study designs for health-promotive self-care interventions using behaviour change theories and consistent follow-up methods to improve data quality.

health promotion, disease prevention and disease control, which is built on increasing personal commitment and responsibility to one's health. An overall accepted definition of self-care in health, and one that guided this review, is acquiring the necessary knowledge, skills and attitudes required to achieve and maintain good health. ${ }^{3}$ In line with the third Sustainable Development Goal of ensuring healthy lives and promoting well-being for all at all ages, ${ }^{4}$ self-care encourages a change in current public health approaches, and explores the processes involved in accessing primary care. Primordial prevention-that is, the prevention of emergent risk factors within a population-is a key consideration in understanding the relationship between self-care and health promotion. ${ }^{5}$ This is important in encouraging non-diseased populations to adopt healthier lifestyles and social values. Health-promoting 


\section{The Self Care Continuum}

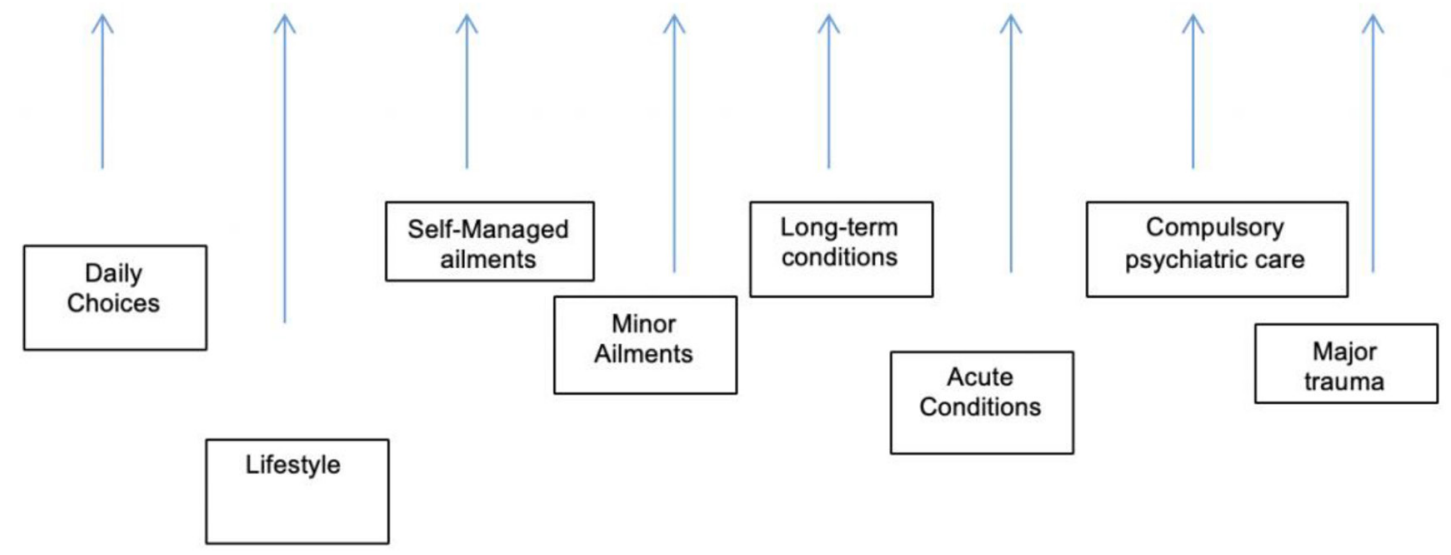

\begin{tabular}{|llll|}
\hline Healthy Living & Minor Ailments & Chronic Conditions & In Hospital Care \\
\hline
\end{tabular}

Figure 1 The self-care continuum. ${ }^{7}$

self-care is one such promising primordial preventative strategy and was the primary focus of this review. ${ }^{56}$

Illness type and an individual's unique situation determine the type of self-care behaviours they undertake. According to the Self Care Forum in the UK, self-care is a continuum ranging from daily health choices to recovery from a major trauma as illustrated in figure $1 .^{7}$ Healthpromoting self-care behaviours would be classified to the left side of the spectrum which covers daily choices, lifestyle and self-managed ailments.

In many high-income countries (HIC), general practitioners (GP) are increasingly devoting a significant amount of time, dealing with minor illnesses, such as fever, cold, sore throats and ear infections, which are often amenable to self-care interventions using home remedies. ${ }^{8} \mathrm{~A}$ rising concern for health systems in countries classified as high income, like the UK, is the increase in non-urgent emergency department attendances, with evidence suggesting that about $40 \%$ of emergency care appointments are diagnosed to be self-managed at home. ${ }^{9}$ When advanced care is sought for minor illnesses, there is an increased financial burden on the healthcare system and an impact on the patient's well-being as a result of being deprioritised in emergency care,${ }^{10}$ highlighting the need for promotive self-care and raising public awareness. Importantly, the ideologies towards self-care and the adoption of its practice are influenced by a country's health system, provision of services, methods of health system financing and social values underlying each system. $^{10}$

Previously, the main focus of self-care research was on self-management of chronic illnesses. There are now wellknown formal programmes, mostly in HICs, designed to provide supported self-management to people with chronic illnesses such as diabetes, asthma, mental illnesses, osteoarthritis and hypertension, and their effectiveness is well established. ${ }^{11}$ Evidence also shows that gender, age, socioeconomic status (SES), self-efficacy and social relationships are determinants in the acceptance and engagement of health-promotive self-care interventions. ${ }^{5}{ }^{12-14}$ There is, however, limited evidence on the effectiveness of such interventions for healthy individuals. This review, therefore, aimed to explore the overall effectiveness of preventative formal self-care programmes for healthy populations, by describing and documenting existing interventions and systematically assessing their effectiveness.

\section{METHODS}

A systematic review of literature with a narrative synthesis ${ }^{15}$ was conducted. This approach focuses on explaining and summarising the findings of multiple heterogeneous studies using text and words. ${ }^{15}$ The research question and its parameters were further refined by applying the Population, Intervention, Comparator, Outcomes, Context and Study design framework to selected studies. ${ }^{16}$ This also guided the development of the inclusion and exclusion criteria (box 1).

\section{Search strategy and study selection}

Literature was identified from: a range of electronic databases (Medline, CINAHAL, EMBASE, PsycINFO, Cochrane Library, Campbell Collaboration, the CostEffectiveness Analysis Registry and Google Scholar); reference tracking of selected articles; and grey literature. The literature search included studies from inception to June 2016 which was the time of undertaking 


\section{Box 1 Inclusion and exclusion criteria}

\section{Inclusion}

- Studies describing a formal programme of supported 'self-care' interventions with a preventative focus and encompassing healthy populations.

- Studies with a clinical study design including randomised controlled trials (RCT), cohort studies, case-control studies, ecological or cross-sectional studies.

- Studies that evaluated the effectiveness of the self-care intervention on health outcomes with a follow-up of more than 3 months.

\section{Exclusion}

- Any study that had interventions that focused on self-management, self-help, self-monitoring or self- efficacy.

- Non-evaluative studies, commentaries and letters to editors.

- Studies that were not explicitly identified by the authors as focusing on self-care programmes or that did not have self-care as a basis for the intervention.

this study. Further articles were identified by reviewing reference lists of all eligible articles. Development of the search strategy started with an initial scoping review on Medline using preliminary search terms that had been agreed on by the review team. Subsequently, three articles that fit the review criteria were used as a template to examine the keywords that it uses to be indexed in databases. A list of these terms (table 1) was then developed and each term entered into PubMed to find its related MeSH terms. Screening of identified literature was guided by the Preferred Reporting Items for Systematic Reviews and Meta-Analyses framework as illustrated in figure $1 .{ }^{17}$ The three-stage screening process involved title screening, abstract screening and full-text screening.

\section{Table 1 Search terms used}

\begin{tabular}{ll}
\hline Self-care & Search terms \\
\hline Evaluation & $\begin{array}{l}\text { self-care OR self AND care OR self } \\
\text { care }\end{array}$ \\
& $\begin{array}{l}\text { evaluation studies OR evaluation } \\
\text { studies as topic OR evaluation } \\
\text { effectiveness AND evaluation } \\
\text { studies OR evaluation studies as } \\
\text { topic OR evaluation }\end{array}$ \\
IIIness prevention & $\begin{array}{l}\text { Illness AND prevention and control } \\
\text { OR prevention AND control } \\
\text { OR prevention and control OR } \\
\text { prevention }\end{array}$ \\
Preventative health & $\begin{array}{l}\text { Preventative AND health OR health } \\
\text { Proactive AND care }\end{array}$ \\
\hline Proactive care & $\begin{array}{l}\text { health promotion OR health AND } \\
\text { promotion OR health promotion } \\
\text { AND programs }\end{array}$ \\
\hline Adult & adult OR adults OR \\
\hline Lifestyle interventions & $\begin{array}{l}\text { life style OR life AND style OR life } \\
\text { style OR lifestyle AND interventions }\end{array}$ \\
\hline
\end{tabular}

\section{Data synthesis and quality assessment of studies}

Self-care interventions are highly heterogeneous in design and outcomes. Therefore, this review analysed the included articles using only a descriptive and narrative synthesis and a meta-analysis was not conducted. Data analysis was focused on evaluating the different measures of health outcomes that indicated behaviour change, and thus the overall effectiveness of self-care interventions for healthy populations. The methodological quality of selected studies was assessed using the Quality Assessment Tool for Quantitative Studies by the Effective Public Health Practice Project. ${ }^{18}$ The quality assessment of the included studies is shown in table 2. This tool was considered suitable as it was specifically developed to evaluate public health studies and is adapted to accommodate for heterogeneity of interventions. ${ }^{18}$ All studies in the review were assessed for selection bias, study design, confounders, blinding, withdrawals and dropouts, intervention integrity and analyses. The scoping, screening and data extraction stages of the review process were independently conducted by two reviewers, and all conflicting ideas were discussed until a consensus was reached. This assessment tool $^{18}$ allows the assessment of each of these sub areas of the study and applies one of the three ratings: strong, moderate or weak, depending on the information provided in the article. A global rating was given for each article where a study is recognised as 'strong' if it had no weak ratings, 'moderate' if it had one weak rating and 'weak' if it had two more weak ratings. The quality assessment was carried out independently. The quality assessment was also carried out independently by two reviewers and any clarifications discussed.

\section{Patient and public involvement}

As this study is a systematic review, this review was conducted without patient involvement. Patients were not invited to comment on the study design and were not consulted to develop patient-relevant outcomes or interpret the results. Patients were not invited to contribute to the writing or editing of this document.

\section{RESULTS}

From the academic database search, 905 articles were identified (see breakdown in figure 2). Seven additional studies that met the inclusion and exclusion criteria were identified through reference lists. A total of 835 articles were excluded after title and abstract screening and 77 articles were left for the full-text review. A total of 16 articles were included in the final review.

The included studies were published between 1982 and 2008 with 12 studies from the USA. The remaining four studies took place in the Islands of Hawaii, ${ }^{19}$ Egypt,${ }^{20}$ Turkey $^{21}$ and the UK. ${ }^{22}$ Based on the assessment, the methodological quality of majority of the studies was rated low with a few studies rated as moderate quality (refer to table 3). The majority of the study designs were randomised controlled trials (RCT),${ }^{23-26}$ quasi 


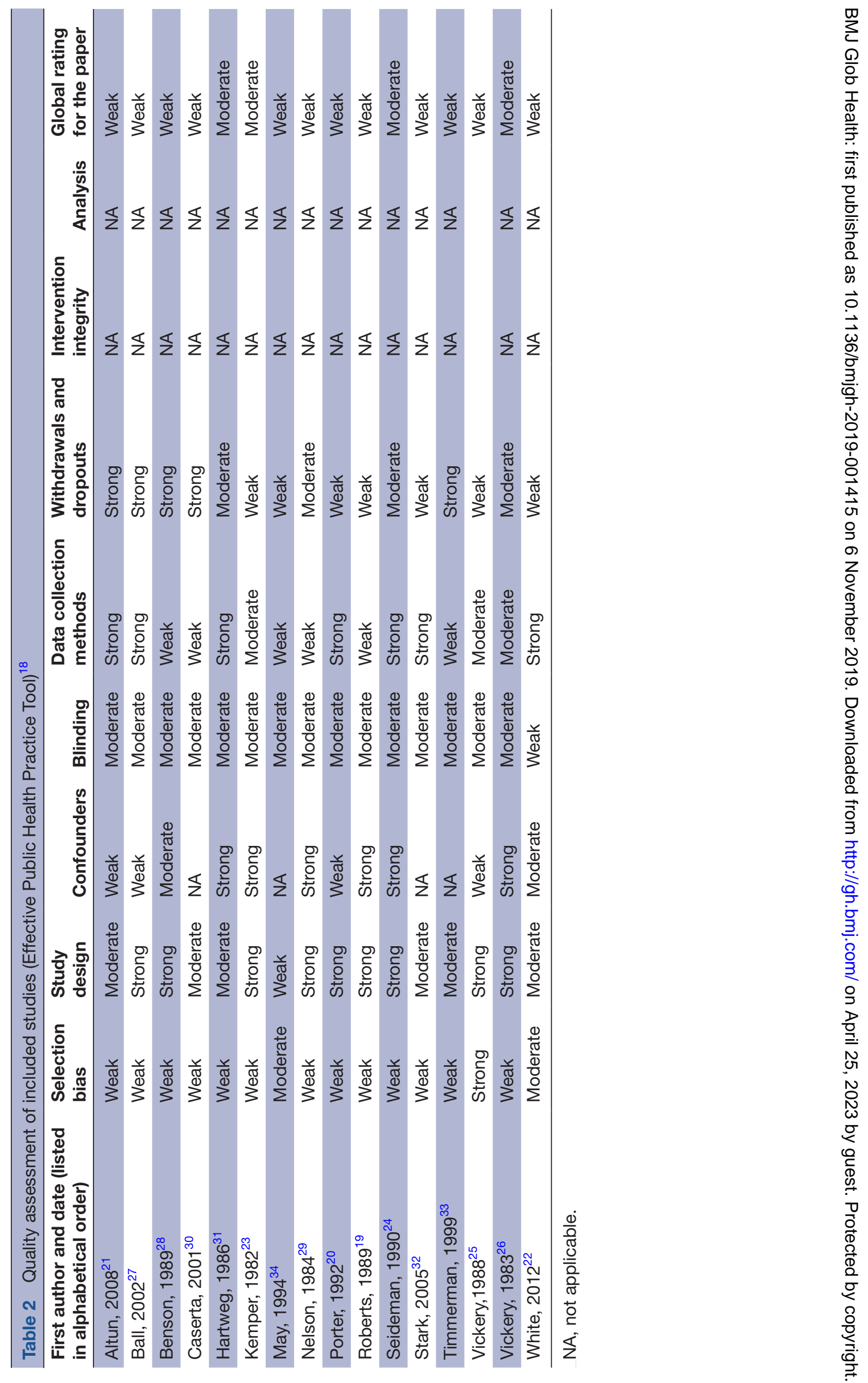



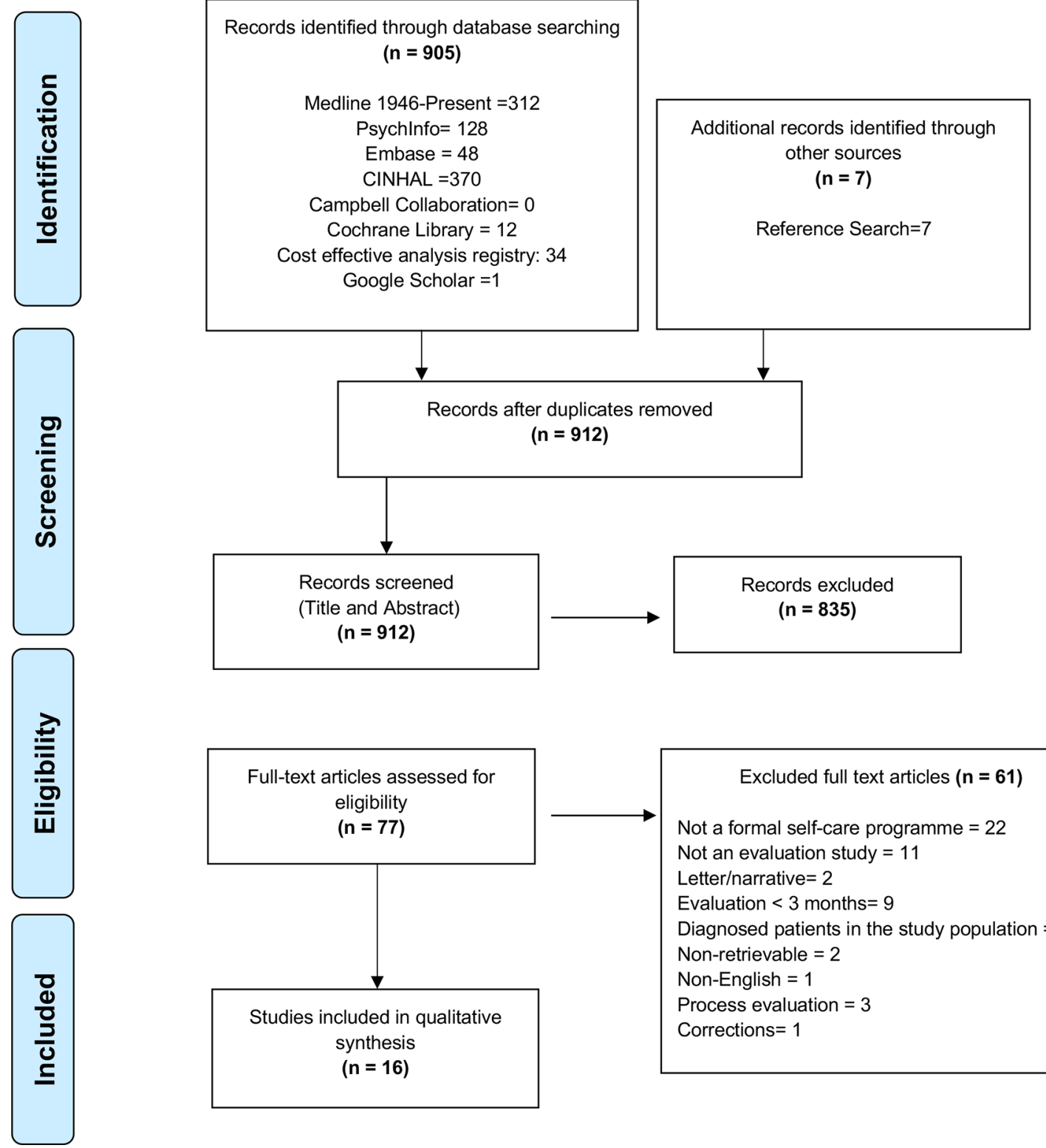

( $n=912)$

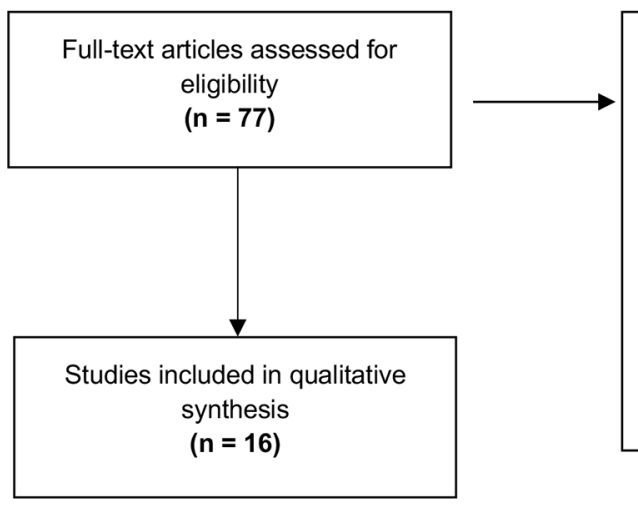

Excluded full text articles $(\mathbf{n}=\mathbf{6 1})$

Not a formal self-care programme $=22$

Not an evaluation study $=11$

Letter $/$ narrative $=2$

Evaluation $<3$ months $=9$

Diagnosed patients in the study population $=10$

Non-retrievable $=2$

Non-English $=1$

Process evaluation $=3$

Corrections $=1$

Figure 2 Preferred Reporting Items for Systematic Reviews and Meta-Analyses (PRISMA) flow diagram.

experimental studies ${ }^{19} 20$ 27-29 and cohort studies..$^{21} 22$ 30-33 The type of evaluation design used for 14 of the selected studies included a pre-post design where the follow-up periods varied in length. ${ }^{19-32}$ The follow-up times ranged from 2 months to 1 year and outcomes were evaluated at multiple points. See table 1 for details of the included studies.

The formal self-care interventions ranged from: university health promotion courses, ${ }^{21} 273133$ community-based educative self-care programmes, ${ }^{19} 20222428-3034$ integrated interventions ${ }^{23}$ and informal interactions. ${ }^{25}{ }^{26}$ The target populations of the selected studies were diverse and included university students, ${ }^{21} 27$ 31-33 the elderly, ${ }^{19}$ 28-30 general clinic population, ${ }^{22} 232526$ the homeless, ${ }^{34}$ Egyptian mothers ${ }^{20}$ and women experiencing moderate or severe menstrual symptoms. ${ }^{24}$ The samples were predominately female in the selected studies. The methods of data collection varied from self-administered questionnaires, standardised data collection tools, independent records and interviews. Programme impact was evaluated in five studies ${ }^{19} 23283034$ and participation rates were not reported in four studies. ${ }^{19} 273234$ Three studies ${ }^{19} 2834$ had positive programme feedback in increasing health knowledge and changing behaviour. All the studies in this review used self-reported data collection methods where participants were asked to recall their behaviours and express their attitudes on a given topic. The included studies in this review were synthesised under three main categories: effectiveness based on intervention characteristics, impact on health-related outcomes and the costeffectiveness of the interventions.

\section{Intervention effectiveness based on mode of delivery}

In the four studies that included a university course, ${ }^{2131-33}$ lectures were the main method of delivery with group discussions, videos, self-assessments and formulation 


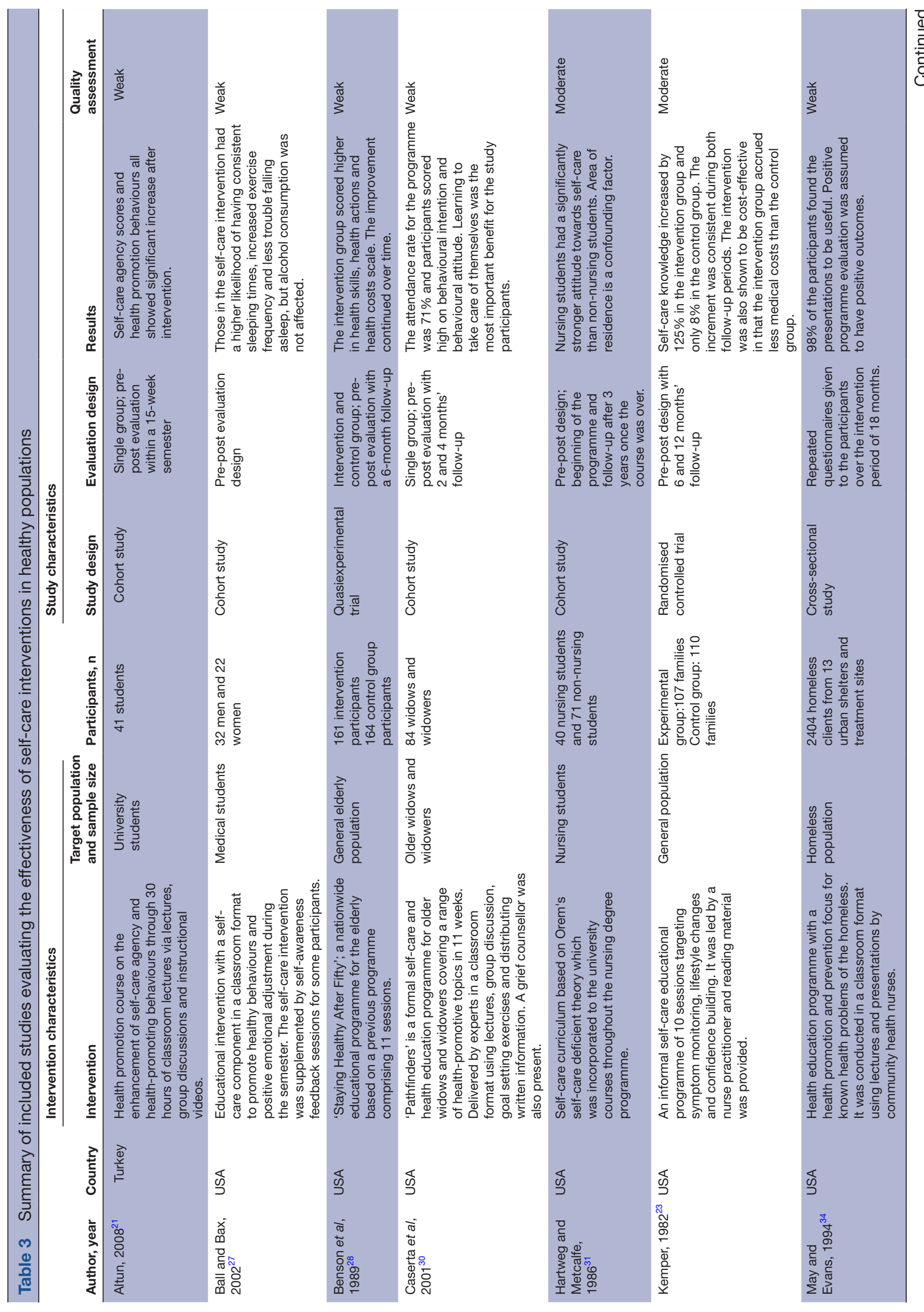




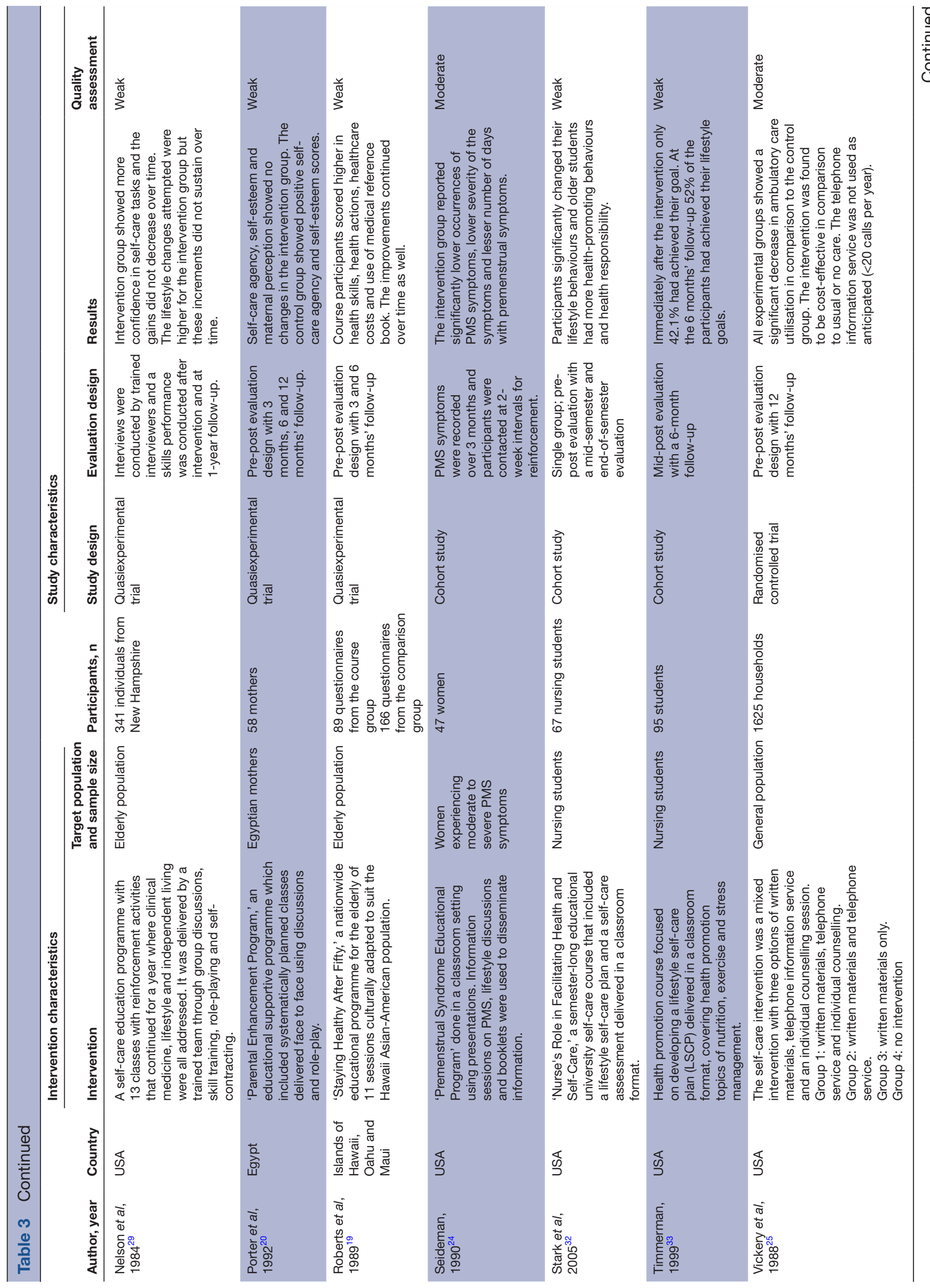




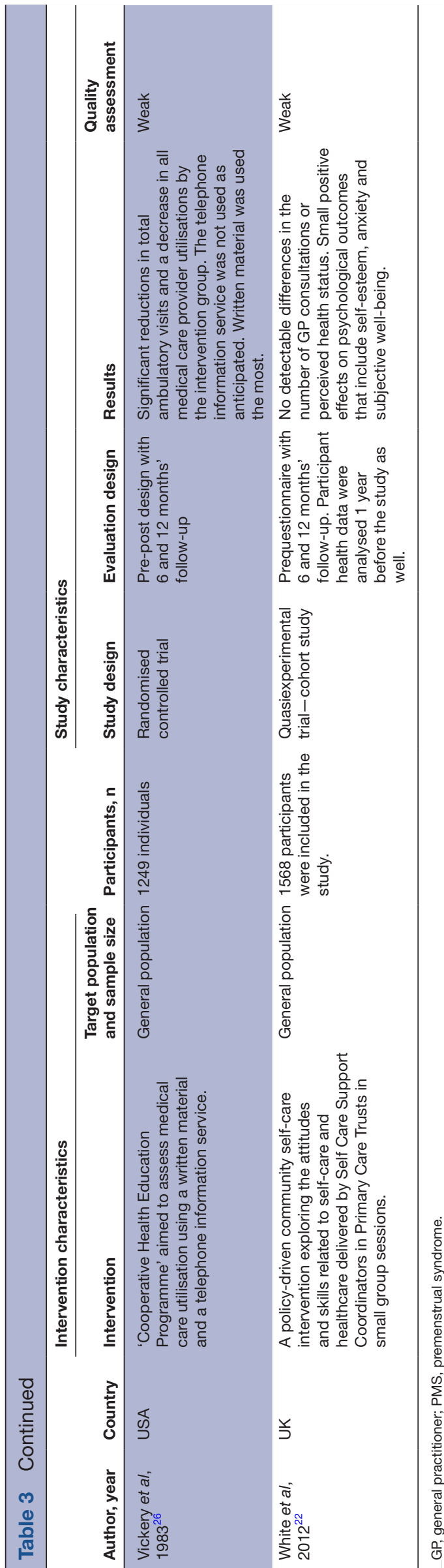

of lifestyle self-care plans used to enhance learning. All four studies had positive effects in improving self-care behaviour, with three of them showing improvements in other health-related outcomes. ${ }^{21} 3132$ Eight studies used face-to-face interventions and positive changes in health-promotive outcomes were in four studies. ${ }^{23} 243034$ However, interventions that were exclusively face to face had no significant impact on medical care utilisation ${ }^{22}$ or on health-related outcomes. ${ }^{20}$

Written materials combined with other methods were used to conduct the intervention in seven studies. Significant improvement in self-care behaviour and other health outcomes was seen in six of the seven studies with mixed findings in the remaining one. Two of the 16 included studies used written materials with a telephone service, ${ }^{25}$ and written materials with one-on-one counselling. ${ }^{26}$ Although the telephone service had very limited use in both studies, a significant decrease in the utilisation of medical services was measured in both. In the intervention group that used written material only as in the mode of information delivery, it was reported to be more cost-effective when combined with one-on-one counselling. ${ }^{26}$

\section{Effectiveness on health-related outcomes}

Self-care interventions were found to be most effective among elderly populations ${ }^{19}{ }^{28-30}$ and student cohorts, ${ }^{21} 2731-33$ with mixed findings among the general population studies. ${ }^{22} 232526$ The change in lifestyle behaviour was maintained in follow-up in two out of the three ${ }^{19} 28$ studies that targeted elderly populations.

Given the heterogeneity of the interventions analysed for this review, there were numerous outcome measures considered. Overall, self-care behaviours that include self-care attitudes, self-care knowledge, self-care strategies and self-care agency were evaluated explicitly in seven studies. ${ }^{20} 212325293133$ Outcomes related to health knowledge, health behaviour, changes in attitudes and lifestyle changes were measured in nine studies. ${ }^{19} 212527-303233$ Only one study conducted a process evaluation. ${ }^{34}$ Utilisation of medical services, which included visits to the GP, ambulatory care, emergency and laboratory care, was measured in seven studies 19222325262829 and costeffectiveness of the intervention was measured in three studies. ${ }^{232526}$ Demographic data were collected from all studies but one. ${ }^{34}$ Other outcomes assessed in the studies were participation rates, depression, maternal perception, self-esteem and programme evaluation outcomes.

Out of the seven studies that examined overall selfcare behaviour as an outcome, four studies showed an improvement in self-care behaviour. ${ }^{21} 232931$ A significant positive increase in self-care knowledge and attitudes and increased confidence to perform self-care tasks like emergency self-checks which included checking for pulse, swollen glands and performing the Heimlich manoeuvre and sustained effects of the improvement in self-care behaviour was highlighted in three studies. ${ }^{23} 2931$ One study targeting mothers of lower SES showed a negative impact on self-care behaviour after the intervention. ${ }^{20}$ 
Lifestyle behaviours such as exercise, stress management, nutrition habits, sleeping behaviour and alcohol consumption were measured in seven studies. ${ }^{19} 21$ 27-29 3233 Two of those studies ${ }^{21}{ }^{32}$ used the Health-Promoting Lifestyle Plan-II scale as a measurement tool. After the intervention, a significant improvement in health-promoting lifestyle changes including health skills and actions was detected in four of the seven studies. ${ }^{19} 212832$ Improved sleeping behaviour and increased exercise frequency was observed in the study by Ball and Bax but no differences in alcohol consumption were detected. ${ }^{27}$

Health attitudes including beliefs and perceptions were examined in four studies ${ }^{19} 2280$ where thoughts about one's emotional self and cognition were recorded. The outcomes showed mixed impact with only small positive effects on anxiety, self-esteem, health literacy and recovery locus control. ${ }^{22}$ Other health outcomes that were evaluated in the studies included premenstrual syndrome symptoms, self-esteem, emotional and academic adjustment and depression which showed no significant or sustained changes over time. ${ }^{20} 2427$ Additionally, an increased ability to communicate with the physician was reported in one study. ${ }^{29}$

\section{Cost-effectiveness of the interventions}

Only 3 of the 16 studies measured cost-effectiveness. In all three, the intervention groups accrued less health costs compared with the control group. ${ }^{2325} 26$ For example, two different studies by Vickery et al on medical self-care education for elders showed cost-benefit ratios of $\$ 2.19^{25}$ and $\$ 2.29-\$ 3.29{ }^{26}$ respectively, for every dollar spent on the intervention. Furthermore, the savings due to decreased medical visits exceeded the intervention costs significantly. Kemper, ${ }^{23}$ in their informal self-care educational programme, also found that the intervention group was more cost-effective than the control group with a cost difference of about $\$ 2.22$ between the groups. In Kemper's study, cost savings per family were $\$ 55.25$ which calculated a cost saving of $\$ 101.27$ per participant. ${ }^{23}$ Significant decreases in hospital and minor illness care utilisation were also reported. ${ }^{26}$ Further, studies done in the USA ${ }^{25} 26$ showed decreased medical care utilisation although the UK study showed no change in the number of GP visits. ${ }^{22}$

\section{DISCUSSION}

The aim of this review was to explore the overall effectiveness of preventative formal self-care programmes for healthy populations in improving health outcomes. The pooled effects of the 16 studies included in this review found mixed evidence for the effectiveness of preventative self-care interventions. Six of the 16 studies included in this review explicitly examined self-care behaviour with four showing improvements in self-care-related behaviour after intervention. Similarly, six of the eight studies that measured health-promotive behavioural change showed positive improvement. Health beliefs and attitudes showed little or no significant change. Self-care interventions were most effective among elderly populations and student cohorts, with mixed findings among the general population. Interventions were found to be cost-effective in comparison to no or usual care in all the three studies that reported this. $87.5 \%$ of the included studies in this review are from HICs with $75 \%$ from the USA. Only two studies (12.5\%) are from low/middleincome countries (LMIC). This indicates that self-care and health promotion for healthy populations is more recognised as a health concern and priority in HICs than LMICs.

Despite the studies in this review having used designs that are considered to be strong or 'gold standard', (RCTs, quasiexperimental or cohort), the generalisability of their results is limited due to sampling and reporting biases, and the lack of consideration for confounding factors. Eight of the 16 studies had small samples and relied on convenience sampling methods which included self-selection of the participants, introducing a volunteer bias. The other eight studies with larger samples had high dropout rates and low participation at follow-up points. The role of the researcher was overlooked in 13 studies where blinding was not discussed at the intervention stages nor in the analysis stages. Furthermore, there was a lack of consideration for confounding factors such as gender, age and level of education which could impact the transferability of the outcomes in practice.

Recording and understanding long-term behaviour change is an existing challenge in the field of health promotion. ${ }^{35}$ The varied and inconsistent patterns of follow-up in the included studies limited the ability of this review to draw conclusive inferences about long-term behaviour change. ${ }^{35}$ A systematic review done in 2011 by Fjeldsoe et al exploring maintenance of behaviour in exercise and dietary changes showed that only $35 \%$ of intervention trials reported maintenance outcomes, and highlighted the importance of recording, reporting and developing a common understanding of behaviour maintenance. ${ }^{36}$ Additionally, a study by Ryan $e t$ al, examining the relationship between health behaviour and the self-determination theory, ${ }^{37}$ showed that addressing an individual's psychological needs such as autonomy, relatedness and competence results in increased engagement and maintenance in health behaviour. Thus, interventions rooted in health promotional theories ${ }^{38}$ that address psychological factors in behaviour change could address the limitations in sustained health behaviour change.

Consistent with previous work by Deeks $e t a l^{39}$ on the effects of gender and age on health behaviours and Acton and Malathum in 2000 on health-promotive selfcare behaviour in adults, ${ }^{5}$ this review found that self-care interventions were most effective in elderly populations. This could potentially be due to their increased engagement with health and social care services compared with younger individuals. Furthermore, as observed in other studies ${ }^{56}$ positive lifestyle behaviour changes were more likely to be sustained in older population groups 
compared with the general population. ${ }^{58}$ This is in line with health promotion theories which posit that younger individuals may have less incentive and motivation to sustain healthy lifestyle behaviours. This could be due to optimistic bias, where one perceives that they are less likely to experience a negative event, or social and cultural influences that limit younger people engage in health-promoting behaviour. ${ }^{38}$

This review also indicates that the interventions were effective in improving self-care and health-promotive behaviour in university students. As the interventions were integrated into academic work, student populations may have a higher incentive to be more compliant to self-care interventions than the general population. Furthermore, the special interest of self-care in nursing students could have additional explanations including that self-care practices are mostly promoted and taught by nurses in clinical settings. ${ }^{32}$ This increases the need for nursing staff to have insight to the practice of developing self-care behaviour plans. ${ }^{32}{ }^{33}$ Nonetheless, studies with medical students have shown more limited effectiveness and poorer health behaviours, ${ }^{40}$ which could be attributed to the nature of the work in the health sector and its various stressors.

Differences in healthcare systems and methods of financing impact on uptake and sustainability of healthpromoting self-care behaviour. This is highlighted in the interventions done in the USA which showed decreased medical care utilisation, with no changes in the number of GP visits for the intervention participants in the UK study. ${ }^{22526}$ An analysis of the Organisation for Economic Co-operation Development healthcare utilisation rates in $2016^{41}$ showed that health systems that are financed through public funds like in the UK have increased utilisation rates. On the contrary, privately financed health systems, like in the USA, may have the 'unintended consequence' of encouraging communities to be more responsive to health interventions due to the direct financial impact of accessing medical services. ${ }^{41} 42$ The role of the broader healthcare system is an area that warrants further investigation. This may provide insight into the impact that the levels of dependency on healthcare and its wider determinants of health-promoting self-care ideologies exist among different populations. ${ }^{56}$

Majority of interventions in this review had a face-toface component in delivery supplemented with written materials and demonstrations. These multicomponent interventions were shown to be more effective than those that were face to face only. Works by Kaufman et at $t^{43}$ and Kiropoulos $e t a l^{4}$ indicate that the impact of faceto-face only interventions in changing health knowledge and behaviour is mixed and dependent on the target behaviour of the intervention, suggesting a need for multicomponent interventions. This review also showed that interventions comprising only written materials were as effective as other interventions that used more engaging techniques, specifically in terms of medical service utilisation. This could have been due to the fact that most of the interventions were group based. Group dynamics have been shown to impact on communication $^{45}$ which could potentially limit the effectiveness of face-to-face communication. In contrast to the findings of this study, a systematic review conducted on the effectiveness of multifaceted interventions by Squires $e t a t^{46}$ showed limited support for multicomponent interventions in comparison to single constituent interventions. This suggests a need for further research examining the effectiveness of different modes and approaches of intervention delivery.

\section{Limitations}

A key limitation of this review was that the majority of studies that were included were published in the 1980s and 1990s. One explanation for the lack of recent studies could be the change and overlap in terminology used in preventative self-care and health education. Over time, terms such as self-management, self-help, self-efficacy and health education have been used synonymously with self-care. Also, many of the recent interventions that focus on prevention do not explicitly mention self-care as a primary outcome, but address specific aspects of selfcare behaviour such as exercise, nutritional habits, sleep patterns or hygiene. ${ }^{478}$ This means that rarely will overall self-care as an outcome in and of itself be evaluated in a formal systematic manner.

Furthermore, this change in terminology over time and lack of a 'globally accepted' definition for formal selfcare interventions created a significant challenge for the authors in limiting the boundaries of the articles to be included in this review. Hence, this review was limited to formal interventions that explicitly looked at 'self-care' as a labelled outcome. While this could have had an impact on the comprehensiveness of the included studies in this review, it is also an indication of the interchangeability of terminology and lack of formal definition for self-care variables in the field of health promotion. Additionally, there was an over-representation of studies from North America (specifically the USA) with little or no representation from all other regions, highlighting the dearth in literature in health-promotive self-care programmes for healthy populations in other regions and particularly in LMICs.

Cultural beliefs and appropriateness are key considerations in understanding the health promotion climate of a setting and play a significant role in health beliefs and behaviour change. ${ }^{49}$ The studies included in this review generally did not consider culture and its impact on healthpromotive self-care behaviour. Thus, the effectiveness and impact of the interventions may be limited as placebo effects that stem from cultural beliefs and implicit personal practices were not captured in these studies.

\section{CONCLUSION}

Self-care initiatives are being encouraged as an important part of healthcare in various forms across the globe. ${ }^{50}$ This review contributes important knowledge to the effectiveness of existing programmes that target 
healthy populations. Nonetheless, the overall evaluation of self-care interventions could be improved if quantitative outcomes were measured using standardised scales, combined with qualitative evidence to capture target users' perspectives. There is a need to develop a systematic framework to define, understand and implement health-promotive self-care interventions across different healthcare settings, and to develop a common global definition for self-care and management. Long-term behaviour change and maintenance should be prioritised in intervention design with consensus among healthcare entities on how to report and measure outcomes over time.

As this review highlights, the cost-effectiveness of health-promotive self-care and reduction of utilisation of medical services could significantly reduce healthcare expenditure. As self-care ideologies vary among health systems, further economic studies that include using quality-adjusted life-years, disability-adjusted lifeyears and economic modelling techniques would help improve understanding of the cost-effectiveness of such interventions. Given the mixed evidence in single versus multicomponent approaches and in general population studies compared with targeted subgroups, special consideration should be given to the methods employed in delivering health-promotive self-care information and to the demographic backgrounds of the target users. This review is a stepping stone to exploring the different aspects involved in designing and implementing selfcare interventions for healthy populations. It also supports a call to action for public health and academic personnel to recognise the gaps and inconsistencies in the existing forms of self-care and the ideologies that govern it, in order to make well-informed decisions in health promotion.

Acknowledgements This publication was funded by Alliance for Health Policy and Systems Research, an international partnership hosted by the World Health Organization, with support from the Norwegian Government Agency for Development Cooperation (Norad), the Swedish International Development Cooperation Agency (Sida) and the UK Department for International Development (DFID). The authors acknowledge Dr Kui W Muraya from the KEMRI Wellcome Trust Research Programme in Kenya, who provided mentorship to NP as a part of the AHPSR research mentorship programme to develop this publication.

Contributors The study idea was developed and discussed between NP and SA. The review design and methodology was developed by both. The review was conducted by NP with the close supervision of SA. NP led the development of the manuscript for publication.

Funding The authors have not declared a specific grant for this research from any funding agency in the public, commercial or not-for-profit sectors.

Competing interests None declared.

Patient consent for publication Not required.

Provenance and peer review Not commissioned; externally peer reviewed.

Data sharing statement Data are available upon reasonable request.

Open access This is an open access article distributed in accordance with the Creative Commons Attribution Non Commercial (CC BY-NC 4.0) license, which permits others to distribute, remix, adapt, build upon this work non-commercially, and license their derivative works on different terms, provided the original work is properly cited, appropriate credit is given, any changes made indicated, and the use is non-commercial. See: http://creativecommons.org/licenses/by-nc/4.0/.

\section{REFERENCES}

1. McGinnis JM, Williams-Russo P, Knickman JR. The case for more active policy attention to health promotion. Health Affairs 2002;21:78-93.

2. Kickbusch I. The contribution of the World Health organization to a new public health and health promotion. Am J Public Health 2003;93:383-8.

3. Simmons SJ. The health-promoting self-care system model: directions for nursing research and practice. Journal of Advanced Nursing 1990;15:1162-6.

4. United Nations. Sustainable development Goals. sustainable development knowledge platform (Internet), 2015. Available: https:// sustainabledevelopment.un.org/?menu=1300 [Accessed 20 Jun 2017].

5. Acton GJ, Malathum P. Basic need status and health-promoting self-care behavior in adults. Western Journal of Nursing Research 2000;22:796-811.

6. Weintraub WS, Daniels SR, Burke LE, et al. Value of primordial and primary prevention for cardiovascular disease a policy.

7. Self-care Forum. What do we mean by self care and why is it good for people? 2016. Available: http://www.selfcareforum.org/aboutus/what-do-we-mean-by-self-care-and-why-is-good-for-people/ [Accessed 10 Jun 2016].

8. Morrell DC, Avery AJ, Watkins CJ. Management of minor illness. BMJ 1980;280:769-71.

9. Watson M, Blair M. Emergency departments and minor illness: some behavioural insights. Arch Dis Child 2018;103:309-10.

10. Gustafsson S, Vikman I, Axelsson K, et al. Self-care for minor illness. Prim Health Care Res Dev 2015;16:71-8.

11. Powers BJ, Olsen MK, Oddone EZ, et al. The effect of a hypertension self-management intervention on diabetes and cholesterol control. The American Journal of Medicine 2009;122:639-46.

12. Dean K. Self-care components of lifestyles: the importance of gender, attitudes and the social situation. Social Science \& Medicine 1989;29:137-52.

13. Dean K. Special Issue Health Self-care components of lifestyles: the importance of gender, attitudes and the social situation. Soc Sci Med 1989;29:137-52.

14. Gillis AJ. Determinants of a health-promoting lifestyle: an integrative review. Journal of Advanced Nursing 1993;18:345-53.

15. Popay J, Roberts H, Sowden A, et al. Guidance on the conduct of narrative synthesis in systematic reviews. A product from the ESRC methods programme Version 2006;1.

16. Higgins JPT, Green S. Cochrane Handbook for systematic reviews of interventions: Wiley online library, 2008.

17. Moher D, Liberati A, Tetzlaff J. Preferred reporting items for systematic reviews and meta-analyses: the PRISMA statement. Annals of Internal Medicine 2009;151:264-9.

18. Effective Public Health Practice Project. Quality Assessment Tool for Quantitative Studies(Internet), 1998. Available: http://www.ephpp. ca/PDF/Quality Assessment Tool_2010_2.pdf. [Accessed 20 Jun 2016].

19. Roberts E, Takenaka JI, Ross CJ, et al. Hawaii Asian-American response to the staying healthy after fifty program. Health Education Quarterly 1989;16:509-27.

20. Porter LS, Youssef M, Shaaban I, et al. Parenting enhancement among Egyptian mothers in a tertiary care setting. Pediatric Nursing 1992;18:329-51.

21. Altun I. Effect of a health promotion course on health promoting behaviours of university students. East Mediterr Health $\mathrm{J}$ 2008;14:880-7.

22. White A, South J, Bagnall A-M, et al. The self-care for people Initiative: the outcome evaluation. Prim Health Care Res Dev 2012;13:382-94.

23. Kemper DW. Self-care education: impact on HMO costs. Med Care 1982;20:710-8.

24. Seideman RY. Effects of a premenstrual syndrome education program on premenstrual symptomatology. Health Care for Women International 1990;11:491-501.

25. Vickery DM, Golaszewski TJ, Wright EC, et al. The effect of selfcare interventions on the use of medical service within a Medicare population. Medical Care 1988;26:580-8.

26. Vickery DM, Kalmer H, Lowry D. Effect of a self-care education program on medical visits. JAMA 1983;250:2952-6.

27. Ball S, Bax A. Self-care in medical education: effectiveness of health-habits interventions for first-year medical students. Acad Med 2002;77:911-7.

28. Benson L, Nelson EC, Napps SE, et al. Evaluation of the staying healthy after fifty educational program: impact on course participants. Health Education Quarterly 1989;16:485-508. 
29. Nelson EC, McHugo G, Schnurr P, et al. Medical self-care education for elders: a controlled trial to evaluate impact. American Journal of Public Health 1984;74:1357-62.

30. Caserta MS, Lund DA, Rice SJ. Participants' attendance at a health promotion program for older widows and widowers. American Journal of Health Education 2001;32:229-36.

31. Hartweg DL, Metcalfe SA. Self-care attitude changes of nursing students enrolled in a self-care curriculum -A longitudinal study. Res. Nurs. Health 1986;9:347-53.

32. Stark MA, Manning-Walsh J, Vliem S. Caring for self while learning to care for others: a challenge for nursing students. Journal of Nursing Education 2005;44:266-70.

33. Timmerman GM. Using self-care strategies to make lifestyle changes. Journal of Holistic Nursing 1999;17:169-83.

34. May KM, Evans GG. Health education for homeless populations. Journal of Community Health Nursing 1994;11:229-37.

35. Rothman AJ. Toward a theory-based analysis of behavioral maintenance. Health Psychology 2000;19(1, Suppl):64-9.

36. Fjeldsoe B, Neuhaus M, Winkler E, et al. Systematic review of maintenance of behavior change following physical activity and dietary interventions. Health Psychology 2011;30:99-109.

37. Ryan RM, Patrick H, Deci EL, et al. Facilitating health behaviour change and its maintenance: interventions based on selfdetermination theory. European Health Psychologist 2008;10:2-5.

38. Brannon L, Feist J. Health psychology. 7th edn. United States of America: Wadsworth: Cengage Learning, 2010: 310-38.

39. Deeks A, Lombard C, Michelmore J, et al. The effects of gender and age on health related behaviors. BMC Public Health 2009;9.

40. Hassed C, de Lisle S, Sullivan G, et al. Enhancing the health of medical students: outcomes of an integrated mindfulness and lifestyle program. Advances in Health Sciences Education 2009;14:387-98.

41. OECD. Health care utilisation OECD Health Statistics (Database); 2016.
42. van Doorslaer E, Wagstaff $\mathrm{A}$, van der Burg $\mathrm{H}$, et al. Equity in the delivery of health care in Europe and the US. Journal of Health Economics 2000;19:553-83.

43. Kaufman J, Synnot A, Ryan R, et al. Face to face interventions for informing or educating parents about early childhood vaccination. The Cochrane Library 2013;46.

44. Kiropoulos LA, Klein B, Austin DW, et al. Is Internet-based CBT for panic disorder and agoraphobia as effective as face-to-face CBT? Journal of Anxiety Disorders 2008;22:1273-84.

45. Frohlich N, Oppenheimer J. Some consequences of e-mail vs. faceto-face communication in experiment. Journal of Economic Behavior \& Organization 1998;35:389-403.

46. Squires JE, Sullivan K, Eccles MP, et al. Are multifaceted interventions more effective than single-component interventions in changing health-care professionals' behaviours? An overview of systematic reviews. Implementation Science 2014;9.

47. Dunn AL, Marcus BH, Kampert JB, et al. Comparison of lifestyle and structured interventions to increase physical activity and cardiorespiratory fitness: a randomized trial. JAMA 1999;281:327-34.

48. Singhal N, Misra A, Shah P, et al. Effects of controlled school-based multi-component model of nutrition and lifestyle interventions on behavior modification, anthropometry and metabolic risk profile of urban Asian Indian adolescents in North India. Eur J Clin Nutr 2010;64:364-73.

49. Kreuter MW, Lukwago SN, Bucholtz RDDC, et al. Achieving cultural appropriateness in health promotion programs: targeted and tailored approaches. Health Educ Behav 2003;30:133-46.

50. World Health Organisation. Self-care in the context of primary health care, 2009. Available: http://apps.searo.who.int/PDS_DOCS/B4301. pdf [Accessed 29 Oct 2018] 